\title{
A INFLUÊNCIA DA VARIABILIDADE DA PRECIPITAÇÃO PLUVIOMÉTRICA NA PRODUÇÃO DE FEIJÃO
}

\author{
Maikeli Kerniski $^{(a)}$, Claudiane Costa ${ }^{(b)}$, Jéssica Borodiak ${ }^{(\mathrm{c})}$ \\ (a) Programa de Pós Graduação, Universidade Estadual do Centro Oeste - UNICENTRO, \\ mk.kerniski@hotmail.com \\ (b) Programa de Pós Graduação , Universidade Estadual do Centro Oeste - UNICENTRO, \\ clau_dianecosta@hotmail.com

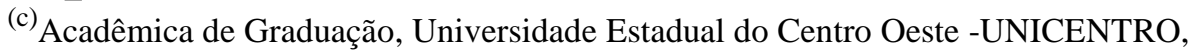 \\ jeborodiak@hotmail.com
}

\section{Eixo: CLIMATOLOGIA EM DIFERENTES NÍVEIS ESCALARES: VARIABILIDADES E MUDANÇAS.}

\begin{abstract}
Resumo
A agricultura desempenha um papel fundamental a produção de alimentos mundial, visando que as populações tenham segurança alimentar. O Feijão é um dos alimentos essenciais para a alimentação brasileira, sua produção é realizada por pequenas e médias propriedades. O clima desemprenha uma importante função para a produção, devido o fator que o feijoeiro é sensível ao estresse hídrico, sendo então fundamental que durante seu cultivo os fatores climáticos propiciem condições adequadas para a produção do feijão. Este trabalho tem por finalidade analisar a variabilidade das precipitações no município de Prudentópolis para a produção do feijão e o seu rendimento e perdas, considerando a precipitação pluviométrica.
\end{abstract}

Palavras Chaves: Feijão, clima, insegurança alimentar.

\section{INTRODUÇÃO}

A produção de alimentos é essencial para a existência de vida no Planeta, atualmente muito se tem debatido sobre a segurança alimentar, que é o acesso suficiente aos alimentos para uma determinada população. Para garantir que todas as pessoas tenham acesso aos alimentos um dos requisitos necessários é a produção realizada através do um sistema conhecido como agricultura. O Centro Tropical de Agricultura Tropical (CIAT) considera que: "Um prato de feijão é o elemento central da dieta de mais de 400 milhões de pessoas nos trópicos. O feijão comum (Phaseolusvulgaris) fornece um alimento altamente nutritivo que contém proteínas, fibras, carboidratos complexos, vitaminas e micronutrientes". Portanto, o feijão fortalece significativamente a segurança alimentar e nutricional principalmente entre os consumidores de baixa renda, reduzindo o risco de doença cardiovascular e diabetes. 
No Brasil vários municípios se destacam na produção, segundo o DERAL (2016), em 2015 Prudentópolis foi $\mathrm{o} 7^{\mathrm{a}}$ produtor de Feijão nacional, onde sua produção apresentou 1,28\% do total nacional. Para garantir então sua produção deve-se levar em consideração as variáreis que comprometem ou alteram o potencial produtivo.

A agricultura é um sistema desenvolvido pela sociedade com o objetivo de obter alimentos, para garantir sua subsistência. Neste contexto a interação com o meio ambiente é essencial no desenvolvimento das plantas, assim o ritmo da disponibilidade de energia e de água de uma região determina o seu potencial de produtividade agrícola (PEREIRA, et al, 2001)

Neste mesmo sentido Mota (1983), salienta que para o desenvolvimento da agricultura, as plantas dependem da constituição genética e das condições ambientais do solo e do clima, ainda que os agricultores saibam mais sobre o manejo do solo do que como explorar os recursos climáticos, em razão de um pensamento de que o conhecimento das relações entre clima e as plantas são de pouco valor prático. Entretanto, os estudos desenvolvido na climatologia pode contribuir para solucionar problemas relacionando a espécie da planta com o clima a qual se adapta.

Para Didonet e Silva (2005) na agricultura são vários fatores que influenciam para que o produtor possa obter maior rentabilidade. Entre outros está às condições climáticas. Para que qualquer empreendimento agrícola tenha sucesso, as respostas interativas entre o clima e a planta precisam ser adequadas. Pensando desta forma é de suma importância conhecer os elementos climáticos que quantificam o clima ao longo dos anos, como a radiação, temperatura do ar e precipitação pluvial entre outros.

Considerando a importância da produção de feijão para a segurança alimentar, e os elementos climáticos como um dos principais agentes responsáveis pela produtividade, este trabalho realizou um recorte temporal dos últimos15 (quinze) anos, buscando compreender se a variabilidade da precipitação pluviométrica interfere na produção de feijão no município de Prudentópolis-Pr.

\section{2. ÁREA DE ESTUDO:}

O município de Prudentópolis está localizado na divisa entre o segundo e o terceiro planalto paranaense na latitude $25^{\circ} 12^{\prime} 47^{\prime \prime}$ S Longitude $50^{\circ} 58^{\prime} 40^{\prime \prime}$ W. Sua altitude é de 840 metros, tendo sua população estimada em 2016 de 51.849 habitantes, (IPARDES, 2017).

De acordo com a classificação de Koppen o município de Prudentópolis obtém o clima subtropical úmido mesotérmico, sendo assim sem estação seca definida, com verões amenos e invernos com geadas severas. 
Devido a esta classificação climática a média das temperaturas do mês mais quente é inferior a $22^{\circ} \mathrm{C}$, e a do mês mais frio é inferior a $18^{\circ} \mathrm{C}$, (MACK, 1968).

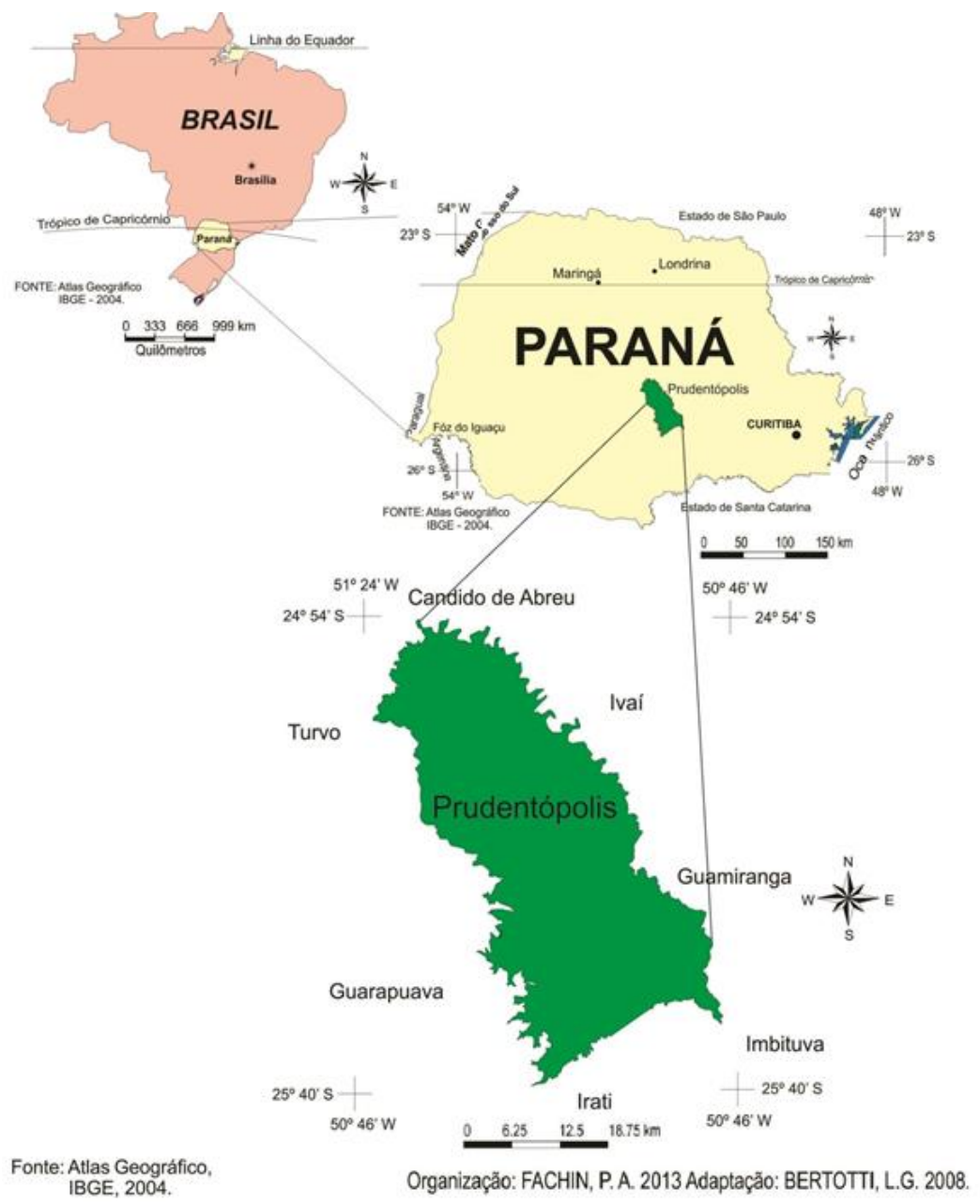

Figura 1: Mapa de localização da área de estudo.

Fonte: FACHIN (2016)

\section{MATÉRIAS E MÉTODOS}

O presente trabalho desenvolveu-se a partir de revisão bibliográfica e utilizou-se de dados pluviométricos disponibilizados pelo Instituto das Águas do Paraná, na plataforma de informações hidrológicas.

No município existem sete estações meteorológicas (Quadro 1), foram utilizados dados de todas, assim estabeleceu uma média entre as mesmas, para elaborar a variabilidade da chuva mensal do município estes dados foram tabulados e elaborados gráficos no Microsoft Office Excel®. Para análise da média mensal da chuva utilizou-se trinta e cinco anos de dados conforme a climatologia recomenda. 


\section{OS DESAFIOS DA GEOGRAFIA FÍSICA NA FRONTEIRA DO CONHECIMENTO \\ Instituto de Geociências - Unicamp \\ Campinas - SP \\ 28 de Junho à 02 de Julho de 2017}

Tabela 1: Localização e altitude das estações meteorológicas.

Fonte; Instituto das água do Paraná, 2017

\begin{tabular}{|c|c|c|c|}
\hline Estação & Latitude (UTM) & Longitude (UTM) & Altitude (m) \\
\hline Boa Vista & 7244220.14 & 462974.55 & 590 \\
\hline Jaciaba & 7252665.14 & 470080.87 & 621 \\
\hline Rio dos Patos & 7212894.92 & 506744.39 & 690 \\
\hline Saltinho & 7218433.07 & 501707.78 & 750 \\
\hline Tijuco & 7192992.78 & 491672.74 & 792 \\
\hline Relógio & 7203695.89 & 489932.23 & 850 \\
\hline Vila Esperança & 7218431.51 & 493280.85 & 750 \\
\hline
\end{tabular}

Os números da produção do feijão foram analisados a partir da base de dados do Instituto Paranaense de desenvolvimento econômico e Social -IPARDES, no qual foi selecionado um recorte de 2000 á 2015, selecionando a quantia plantada em hectares e o rendimento médio, os dados foram tabulados e analisados.

Para a análise da precipitação em relação à produtividade de feijão foram utilizados dados apenas dos meses que ocorre a safra de agosto a abril, pois é nestes meses que pode ou não ocorrer interferência na produção, seja desde a germinação da semente até a colheita. Ainda no Microsoft Office Excel® foi realizada uma média para o período das safras. O qual foi utilizado nas comparações com a produção do feijão.

O início do período de produção do feijão conhecido como feijão das águas inicia em agosto, o qual pode se prolongar até os meses se setembro, devido as condições climáticas, após o plantio não pode mais haver geadas, as quais podem prejudicar o desenvolvimento da planta. A colheita é feita nos meses de Dezembro e Janeiro, dependendo de quando foi plantado. A outra safra se inicia em faneiro e Fevereiro se estendendo até março a abril quando acontece a colheita.

Levando em consideração que a precipitação pluviométrica é apenas um dos agentes que interfere na produção, também foi realizada uma análise entre a área colhida e a produção média, para visualizar em quais anos havia uma disparidade, sendo assim se recorreu as alturas da precipitação para entender se a mesma auxiliou no resultado.

Para esta relação foram utilizados 15 anos de dados tanto da precipitação pluviométrica quanto da produção de feijão, conforme obteve-se disponibilidade ambas as variáveis. 


\section{RESULTADOS DISCUSSÕES E}

28 de Junho à 02 de Julho de 2017

\subsection{Produção do feijão no Município de Prudentópolis}

O cultivo do Feijão no município de Prudentópolis é realizado principalmente por pequenas e médias propriedades as quais se definem como agricultura familiar que realizam o cultivo de forma manual, na qual apresentam duas características diferentes de cultivo: práticas agrícolas modernas com utilização de insumos agrícolas e utilização de adubos; sistema que não utiliza adubo, e a semente utilizada é resultado de safras anteriores, onde as sementes não passam por tratamentos industriais, e o outro é o sistema de roça de toco no qual Kerniski (2013) define como:

Os procedimentos do sistema de roça de toco são: a) roçada da área a ser queimada; b) é aguardado secagem da matéria vegetal; c) queima da matéria seca; d) plantio do feijão. O plantio deve ser feito após a queimada, para aproveitar as cinzas que são consideras como fertilizantes. Os produtores da roça de toco, afirmam que o fogo é utilizado principalmente para a economia do trabalho, pois favorece a limpeza do terreno.

Este último sistema é o mais utilizado pelos agricultores, devido principalmente a declividade do solo, e falta de recursos para modernizar a agricultura, uma de suas principais características é a queimada e o pousio, todos os procedimentos utilizados para a prática são manuais, sem equipamentos mecanizados, adubos químicos, e agrotóxicos.

Como a maioria das culturas, o feijoeiro é sensível aos estresses hídricos, seja pelo déficit de água, seja pelo excesso. Assim, urge a necessidade de propiciar condições ambientais mais favoráveis para otimizar a produtividade da cultura.

\subsection{A Precipitação Pluviométrica no município de Prudentópolis:}

A precipitação Pluviométrica em Prudentópolis varia entre 80 e 200 milímetros ao longo dos meses. Os mais chuvosos são outubro, dezembro, janeiro e fevereiro o mês menos chuvoso é agosto como pode ser observado na Figura 2. Sendo assim percebe-se que há uma variabilidade da altura da precipitação nos diferentes meses. 


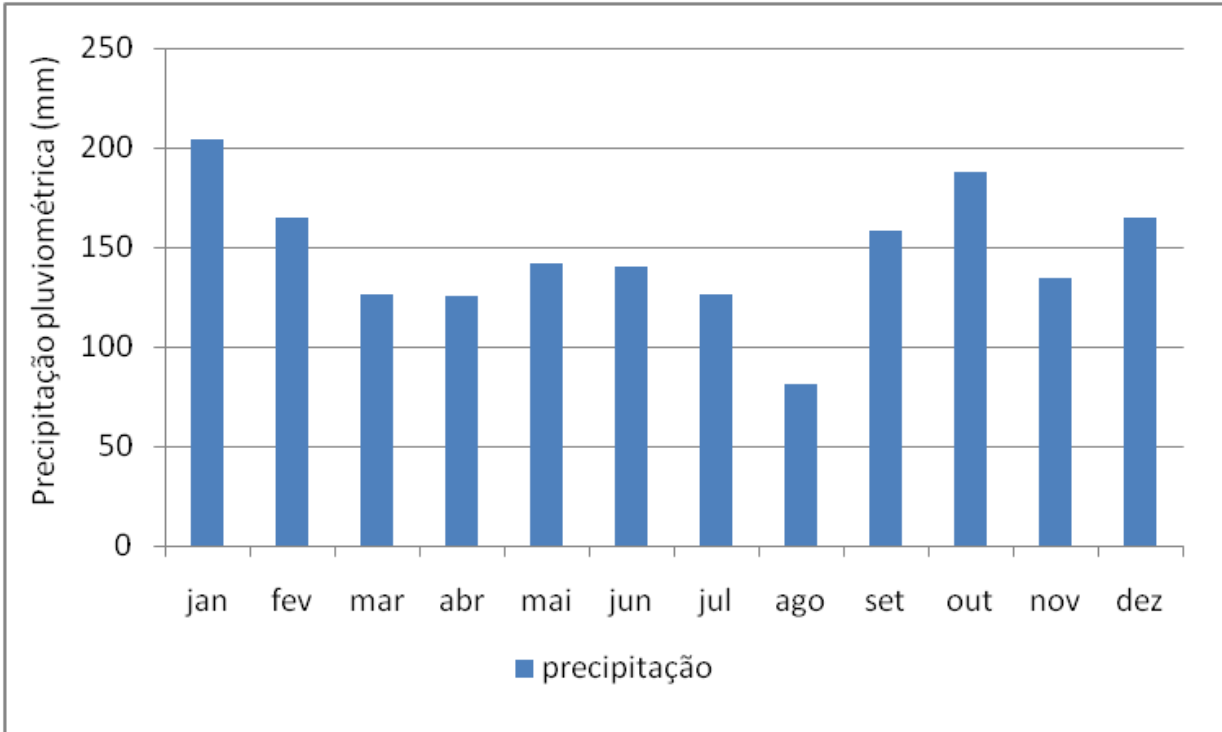

Figura 2: Média mensal da Precipitação (1980-2015).

Fonte: Instituto das águas do Paraná, 2017.

\subsection{Balanço Hídrico de Prudentópolis}

O balanço hídrico também é importante para entender o déficit e o excedente hídrico de um devido local. Neste sentido Borodiak, (2016) apresenta o balanço hídrico do município de Prudentópolis, assim é possível observar que o valor máximo de precipitação ocorre na estação do Relógio, com $1.851 \mathrm{~mm}$. Essa estação está localizada no ponto mais alto em relação às demais estações. Já o valor mínimo de precipitação $(1.655 \mathrm{~mm})$, está localizada na estação de Jaciaba, altitude de 621 metros, uma das mais baixas comparada com as demais. 
XVII Simpósio Brasileiro de Geografia Fisica Aplicada

I Congresso Nacional de Geografia Física
OS DESAFIOS DA GEOGRAFIA FÍSICA NA FRONTEIRA DO CONHECIMENTO

Instituto de Geociências - Unicamp

Campinas - SP

28 de Junho à 02 de Julho de 2017

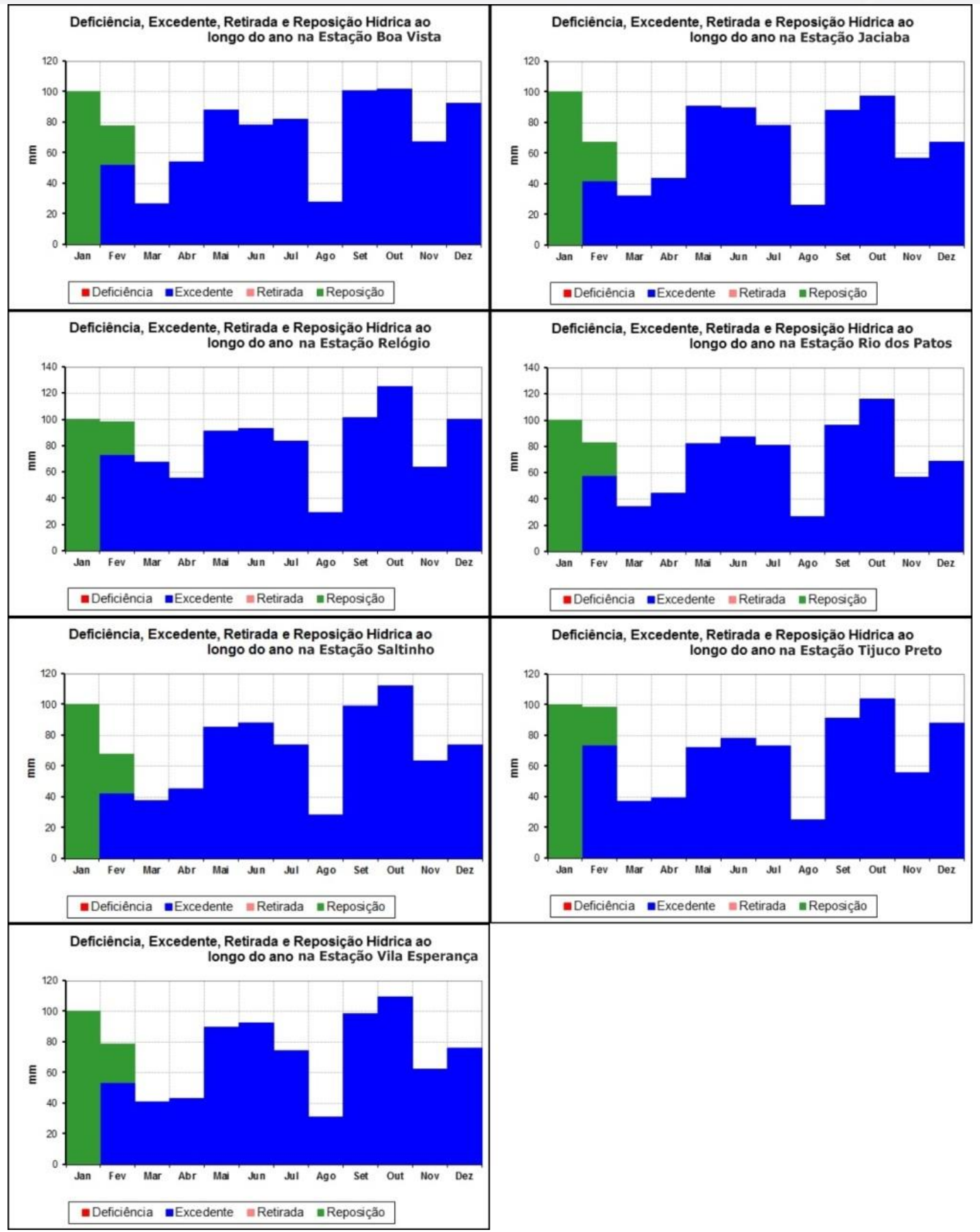

Figura 3- Gráficos do Balanço Hídrico para cada estação.

Fonte: Borodiak, 2016.

A partir das análises realizadas de todas as estações meteorológicas é perceptível que o município dispõe excedente hídrico durante o período que vai de fevereiro a dezembro e consta como reposição nos meses de janeiro e fevereiro, período que ocorrem as maiores temperaturas. O município de Prudentópolis possui elevados índices de precipitação, com grande disponibilidade de recursos hídricos. Porém, para 
determinadas culturas e plantios, esse excedente hídrico pode não ser muito benéfico, (BORODIAK, 2016).

Em escala local, no caso de uma determinada cultura, o balanço hídrico tem por objetivo estipular a variação de disponibilidade de água no solo. Conhecendo qual a quantidade de água no solo ou qual a umidade, é possível estabelecer se a cultura está sofrendo estresse hídrico. No município de Prudentópolis, o período mais úmido é no verão, onde a temperatura do ar é maior, consequentemente, há uma alta evaporação e evapotranspiração, (BORODIAK, 2016).

\subsection{Relação entre a área colhida com o rendimento médio do feijão}

Os fatores que influenciam na produção do feijão podem ser endógenos (fatores relacionados as características físicas, biológicas e químicas do solo) exógenos (relacionados as variabilidade da precipitação pluviométrica as temperaturas dentre outros), e ainda característicos da forma com que o agricultor desenvolve o plantio.

Para compreender a influência da chuva foi analisado o rendimento médio, que se dá através da divisão da área plantada em hectares com a quantidade produzida em kl/ha. Conforme a interpretação da figura 4, á uma variabilidade entre rendimento médio e a área plantada. Os anos que mais apresenta este fator é em 2006 e 2009, onde a área plantada é maior que nos outros anos mas o rendimento médio em relação a área plantada é menor. Nos anos seguintes diminui a área de plantação, mas a produção aumenta.

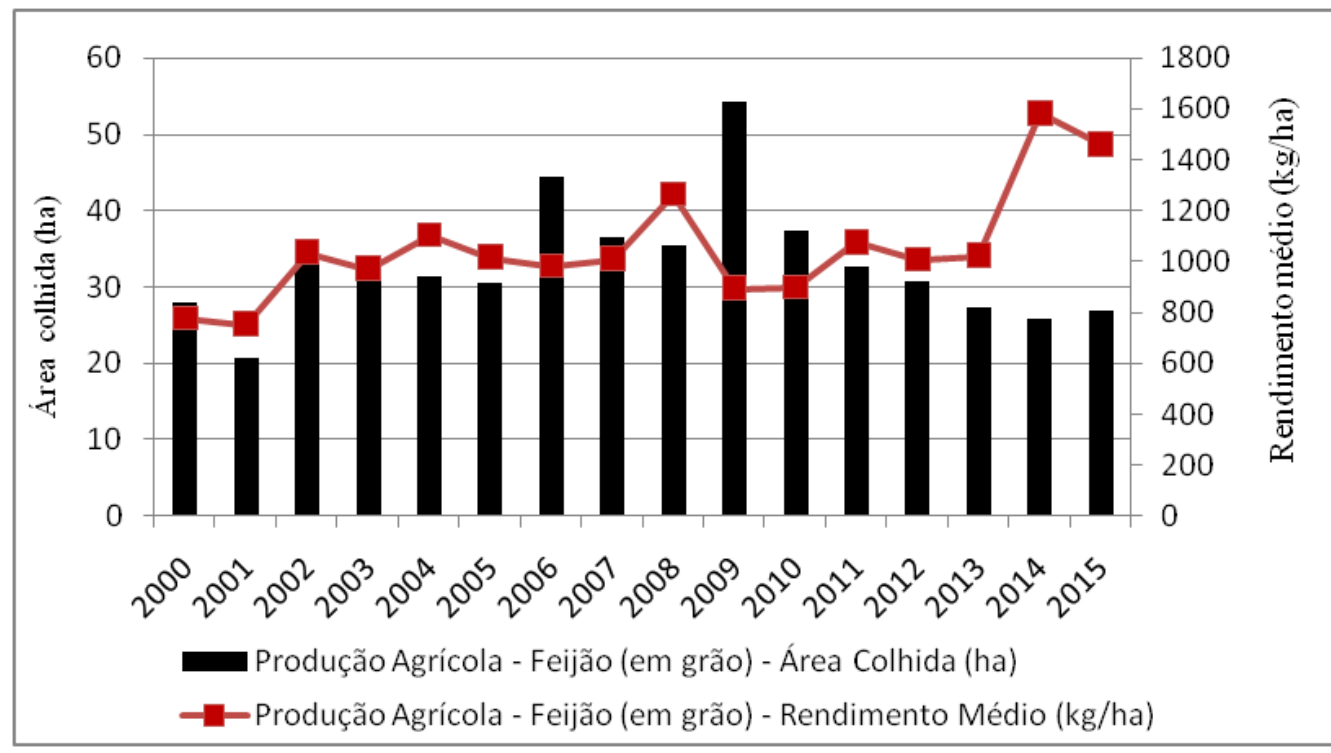

Figura 4: Área colhida e rendimento médio da produção de feijão em Prudentópolis Fonte: Elaborado pelas autoras. 
XVII Simpósio Brasileiro

de Geografia Fisica Aplicada

I Congresso Nacional

de Geografia Física
OS DESAFIOS DA GEOGRAFIA FÍSICA NA FRONTEIRA DO CONHECIMENTO

Instituto de Geociências - Unicamp

Campinas - SP

28 de Junho à 02 de Julho de 2017

\subsection{Impactos da Precipitação pluviométrica na produção de Feijão:}

A precipitação pluviométrica, é de suma importância, pois a estimativa de consumo hídrico do feijoeiro varia de 300 a $600 \mathrm{~mm}$, bem distribuídas ao longo do seu ciclo, sendo o consumo diário de 3 a $4 \mathrm{~mm}$ e disponibilidade mensal mínima de 100 mm (DOURADO-NETO \& FANCELLI, 2000).

$\mathrm{Na}$ produção do município de Prudentópolis os anos em que se obteve melhor produtividade estão acompanhados de uma média de 1.400 milímetros. Como observado na Figura 5, mas alguns anos se destacam. No ano de 2006 destacados na análise da a área colhida com relação à produção observa-se que a precipitação esteve dentro da média esperada para o período, mas se consideramos o total mensal recorrendo às estações meteorológicas, no mês de dezembro houve uma altura média de precipitação de 196 milímetros. Sendo que em uma das estações (estação Boa Vista) utilizadas para este trabalho a qual fica na zona rural do município registrou dados muito acima da média uma altura de 307 milímetros.

Esse fator é de grande importância, pois este um dos meses de colheita do feijão, o que pode causar perdas, considerando que os pequenos produtores não tem acesso as maquinas agrícolas modernizadas para a colheita, a mesma é realizada manualmente, o que demanda um tempo maior para essa etapa, ficando suscetível aos elementos climáticos.

No ano de 2009 o rendimento médio foi de $895 \mathrm{~kg} / \mathrm{ha}$, sendo que neste período está evidente as grandes alturas de precipitação muito acima da média esperada para o período das safras. Sendo assim, a chuva influenciou de forma considerável na produção. No ano de 2010 embora a chuva esteja dentro da média esperada, a baixa produção está ligada a área colhida, pois neste ano a área foi menor.

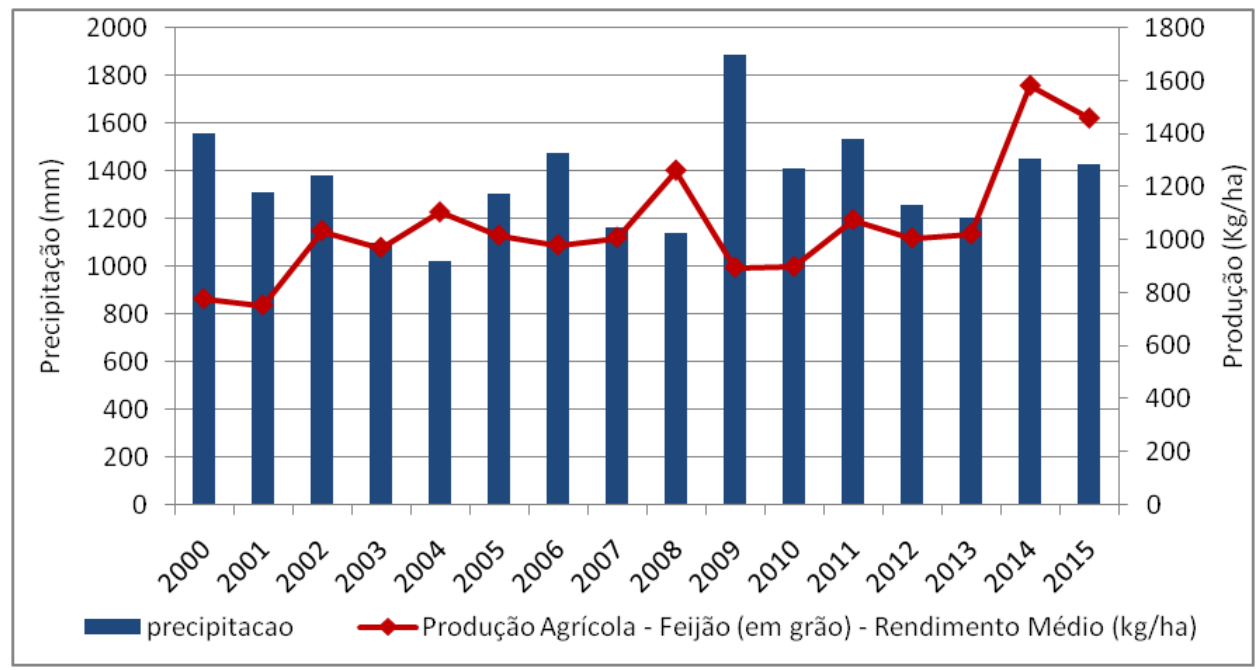

Figura 5: Relação entre a precipitação pluviométrica e a produção de feijão (dados relacionados aos meses de safra)

Fonte: Instituto das águas do Paraná/ IPARDES, 2017 
Segundo GUIMARÃES (1998), a intensidade dos danos provocados pelo estresse depende da duração, intensidade, frequência e época de sua ocorrência. Em sementes, a deficiência hídrica provoca redução da germinação; no período vegetativo, ocorre, além de outros efeitos, a redução de área foliar; durante a floração provoca abscisão de flores, com consequente redução do número de vagens por planta e, no enchimento de grãos, reduz o número de grãos e peso de vagens.

\section{CONSIDERAÇÕES FINAIS}

A partir das análises realizadas foi possível observar que a produção de feijão depende de vários fatores, o tipo de solo e os nutrientes que formam sua composição são de total importância. Os fatores exógenos como a precipitação pluviométrica também é de suma importância, assim interferindo na produção. Quando há excesso de chuva pode ocasionar perdas irreparáveis. Já no caso de déficit hídrico pode ser reparado com a irrigação, o que acontece em outras regiões do país.

Dessa forma constata-se que no município de Prudentópolis a precipitação pluviométrica interfere no rendimento da produção de feijão. Como o município está localizado em uma região que as chuvas são abundantes esta variável dependo do mês e da quantidade de água no solo pode ocasionar perdas, como aconteceu no ano de 2009, onde foi maior área colhida dentre os anos da pesquisa realizada, e ocorreu a maior perda em virtude das grandes alturas de precipitação pluviométrica.

\section{REFERÊNCIAS:}

\section{BORODIAK, J. Estimativa do balanço hídrico climatológico de}

Prudentópolis. Anais de evento. Disponível em; http://anais.unicentro.br/eaic/pdf/xxvv2n1/561.pdf> Acesso em fevereiro de 2017.

DIDONETE, A.D. e SILVA, S.C. Cultivo do Feijão Irrigado na Região Noroeste de Minas Gerais. EMBRAPA, 2005. Disponível em: <http://sistemasdeproducao.cnptia.embrapa.br/FontesHTML/Feijao/FeijaoIrrigadoNoroesteMG/clima.ht. Acesso em outubro de 2016. 
DERAL (2014) Feijão - Análise da conjuntura da produção de 2014, disponível em : http://www.agricultura.pr.gov.br/arquivos/File/deral/Prognosticos/feijao_2014_15.pdf, acesso 09 de março de 2017.

DOURADO-NETO, D.; FANCELLI, A. L. Descrição dos estádios fenológicos e ecofisiologia. In: Produção de feijão. Guaíba: Agropecuária, 2000, p. 33-45.

FACHIN P. A ( 2016) O Efeito da queimada na condutividade hidráulica do solo em Agricultura de Roça de Toco. Revista Geoambiente. GO, disponível em : http://www.revistas.ufg.br/geoambiente/article/view/42251/22035, acesso em 10 de fevereiro de 2017.

HOFFMANN, Rodolfo. Pobreza, insegurança alimentar e desnutrição no Brasil. Estud. av., São Paulo, v.9, n.24, p.159-172, . Agosto 1995

$<$ http://www.scielo.br/scielo.php?script=sci_arttext\&pid=S0103-

40141995000200007\&lng=en\&nrm=iso>. Acesso em 15 Mar. 2017

IPARDES, Instituto paranaense de desenvolvimento Econômico e Social. Plataforma; Cadernos municipais. Disponível em:

http://www.ipardes.gov.br/cadernos/MontaCadPdf1.php?Municipio=84400\&btOk=ok Acesso em: Janeiro de 2017.

KERniSKi M. M (2013) A prática de Roça de Toco no sistema de Faxinal Tijuco Preto. Rede Cepial, disponível em: http://sites.uepg.br/ppgg/Public/publicacao/ANAIS_IV_CEPIAL_X.pdf, acesso em 25 de Fevereiro de 2017.

MOTA, F. S. Meteorologia agrícola. São Paulo: Nobel,1983.

MAACK,

R.

Geografia

física

dhttp://sites.uepg.br/ppgg/Public/publicacao/ANAIS_IV_CEPIAL_X.pdfo Estado do Paraná. Curitiba: José Olympio, 1968.

PEREIRA, A.R. ANGELOCCI, L.R. SENTELHAS, P.C. Agrometeorologia: Fundamentos e aplicações Práticas. Guaíba: Agropecuária, 20 